Check for updates

Cite this: RSC Adv., 2019, 9, 13550

Received 25th December 2018 Accepted 23rd April 2019

DOI: $10.1039 / \mathrm{c} 8 \mathrm{ra10559f}$

rsc.li/rsc-advances

\section{Effect of electron beam irradiation on the structural characteristics and functional properties of rice proteins}

\author{
Xinxia Zhang, ${ }^{\text {abc }}$ Li Wang, ${ }^{\text {abc }}$ Zhengxing Chen, (iD abc Yongfu Li, ${ }^{\text {ab }}$ Xiaohu Luo ${ }^{a b c}$ \\ and Yanan $\mathrm{Li}^{\mathrm{abc}}$
}

A study of the structural and functional changes of rice proteins (RPs) induced by electron beam irradiation (EBI) at 5 kGy, 10 kGy, 20 kGy, and 30 kGy was performed. The microcosmic surface structures of the RPs were changed and fragmented due to irradiation damage occurring on the RP surfaces. The changes in the UV visible spectra, intrinsic fluorescence spectra, surface hydrophobicity and SH and SS group contents indicated that the RPs unfolded after EBI treatment. In addition, the degree of conformational change was increased with increasing EBI treatment doses. FTIR analysis showed that the secondary structure redistributed, showing decreases in $\alpha$-helices and concomitant increases in $\beta$-sheets, $\beta$-turns and random coils. The functional properties, emulsifying abilities, water adsorption capacities and oil adsorption capacities of the irradiated RPs improved dose-dependently, with maximums occurring at 30 kGy. The foaming properties were also enhanced by EBI; however, this effect was not dose-dependent. In contrast, all of the samples irradiated by electron beams presented lower emulsion stability than the control ( $0 \mathrm{kGy}$ ). These results provide a theoretical basis for the application of $\mathrm{EBI}$ in improving protein properties in the future.

\section{Introduction}

Rice proteins (RPs) are rice byproducts produced during the starch extraction process. ${ }^{\mathbf{1} 2}$ RPs exhibit hypoallergenic activity ${ }^{\mathbf{3}}$ and high protein efficiency ratios, ${ }^{4}$ which makes them good protein sources for human nutrition and even as suitable ingredients for infant food formulations. ${ }^{5}$ RPs are also attracting much interest in the food industry because they are plentiful and readily available. ${ }^{6,7}$ In addition, the hydrolysates of rice protein have crucial biological activities, including anti-oxidative, $^{8}$ antiatherogenic ${ }^{9}$ and ACE-inhibitory properties. ${ }^{\mathbf{1 0}}$ However, the utility of RDPs in the food industry is limited by their low digestibility and select functional properties. ${ }^{11}$ To obtain ideal properties, many technologies have been applied to improve the properties of the proteins, such as enzymatic hydrolysis $^{8}$ and physical ${ }^{12}$ or chemical ${ }^{13}$ methods. Food irradiation is an emerging physical method used in the food industry to maintain nutritional properties and modify food properties.

${ }^{a}$ State Key Laboratory of Food Science and Technology, Jiangnan University, Wuxi, 214122, China. E-mail:wangli0318@jiangnan.edu.cn; zxchen_2008@126.com; Fax: +86-510-8519-7856; Tel: +86-510-8519-7856

${ }^{b}$ National Engineering Laboratory for Cereal Fermentation Technology, Jiangnan University, Wuxi, 214122, China

'Jiangsu Provincial Research Center for Bioactive Product Processing Technology, Jiangnan University, Lihu Road 1800, Wuxi, 214122, China
In recent years, studies of the application of irradiation technology on food protein modification have gradually increased and have primarily focused on physiochemical and functional properties. Shawrang et al. demonstrated that the emulsifying properties of protein in soybean meal were effectively improved by $\gamma$-irradiation. This improvement may be attributable to protein unfolding and scission induced by $\gamma$ irradiation. Such changes in protein structure could expose more hydrophobic amino acids, which have a close relationship with protein functional properties. ${ }^{14}$ It has also been found that 2.98 kGy irradiation had enormous effects on the foaming properties of egg white protein, mainly because of conformational conversion and increased surface hydrophobicity induced by $\gamma$-irradiation. ${ }^{15}$ In addition, the viscosity of irradiated liquid egg whites decreased significantly with increases in the irradiation dose level. This may be due to the chain scission of proteins induced by the irradiation. Scission of proteins reduces the number of peptide linkages and thereby decreases the viscosity. ${ }^{16}$

There are many categories of irradiation technologies, one of which is electron beam irradiation (EBI). Compared to the other irradiation methods, EBI is highly attractive in terms of great effectiveness, flexibility, cold process use and environmental friendliness. ${ }^{17}$ Several research groups have found that the use of EBI could modify the functional properties of food proteins. $^{2,18}$ The application of EBI has also been reported by Wang et al., showing that the antioxidant activity of pea protein 
hydrolysates was effectively improved. ${ }^{2}$ Moreover, Akbarian et al. reported that EBI technology was applied during research into the digestion properties of soybeans. ${ }^{19}$

Rice protein has abundant nutritional value. However, the effect of EBI on rice protein has not yet been studied. To date, there is not a sufficient understanding of the structural characteristics and functional properties of rice protein irradiated by EBI. This study concentrated on elucidating the effects of EBI on rice protein. Therefore, the changes in the structural and functional properties of RPs induced by EBI have been evaluated. The results of this study are expected to provide a theoretical basis for the development of the electron beam irradiation technique and provide technical support for the further improvement of rice protein.

\section{Materials and methods}

\subsection{Materials}

Rice protein $(82.9 \%$ protein, $7.9 \%$ water, $1.35 \%$ ash, $6.25 \%$ lipid, $1.60 \%$ sugar) was provided by Shanyuan Biotechnology Co. Ltd. (Wuxi, China), and 5,5'-dithio-bis-2-nitrobenzoic acid (DTNB) and 1-anilino-8-naphthalene-sulfonate (ANS) were purchased from Sigma (St. Louis, MO, USA). All chemicals and reagents were analytical grade or higher.

\subsection{Electron beam treatment}

Electron beam irradiation was conducted by the AIBANG EBTech Co., Ltd. (Wuxi, China) using a high-energy linear accelerator. $100 \mathrm{~g}$ of rice protein was sealed in each sterile food-grade polyethylene plastic bag at a final thickness of $1.00 \mathrm{~cm}$. Then, the rice protein was irradiated with varying doses $(5 \mathrm{kGy}, 10 \mathrm{kGy}$, $20 \mathrm{kGy}$, or $30 \mathrm{kGy}$ ) by electron beam irradiation at $5.0 \mathrm{MeV}$. The rice protein was irradiated in powder form. All irradiations were performed at room temperature. After irradiation, samples were stored at $-20{ }^{\circ} \mathrm{C}$ until further use.

\subsection{Scanning electron microscopy (SEM)}

The protein was adhered to a circular aluminum specimen stub by an adhesive tape and coated with gold-palladium for $90 \mathrm{~s}$ under the condition that the current was $15 \mathrm{~mA}$. Then, the microcosmic surface structures of the sample granules were photographed under a potential of $5 \mathrm{kV}$ with a scanning electron microscope FEI Quanta ${ }^{\mathrm{TM}} 200$ (FEI Co., Hillsboro, USA). The surface structures of the samples were observed at $2400 \times$ magnification.

\subsection{UV visible spectrum}

Protein solutions were prepared in phosphate buffer $(10 \mathrm{mM}$, $\mathrm{pH}$ 8.0) and stirred for $20 \mathrm{~min}$, then centrifuged at $5000 \mathrm{rpm}$ for $10 \mathrm{~min}$. The protein concentration in the supernatant was measured according to the Bradford method..$^{20}$ Before being used, the sample solution was diluted to concentrations of $2 \mathrm{mg}$ $\mathrm{mL}^{-1}$. The UV visible spectra of the sample solutions were recorded at 200-400 $\mathrm{nm}$ with a Varian Cary 100 UV-vis spectrophotometer (Varian Inc., Palo Alto, USA) at $25{ }^{\circ} \mathrm{C}$. The scanning speed was $60 \mathrm{~nm} \min ^{-1}$, and the silt was $2.0 \mathrm{~nm}$. For the blank, the phosphate buffer (0.01 M, pH 8.0) was used.

\subsection{Fourier transform infrared spectroscopy (FTIR) analysis}

FTIR spectroscopy was recorded using a Nicolet iS10 FTIR spectrometer (ThermoFisher Scientific, Marietta, OH, USA). Protein powder ( $2 \mathrm{mg}$ ) was mixed with $\mathrm{KBr}$, grounded, and then pressed into a pellet. Spectra were measured in a wavenumber range of $4000-400 \mathrm{~cm}^{-1}$ at a $2 \mathrm{~cm}^{-1}$ resolution. Omnic V8.1 (ThermoFisher Scientific, USA) and PeakFit 4.12 (SeaSolve Software Inc., USA) were used for determination of $\alpha$-helices, $\beta$ sheets, turns and unordered structure percentages in the protein mixtures.

\subsection{Intrinsic fluorescence spectroscopy (IFS)}

Protein solutions were prepared in phosphate buffer $(10 \mathrm{mM}$, $\mathrm{pH}$ 7.0) and stirred for $20 \mathrm{~min}$, then centrifuged at $5000 \mathrm{rpm}$ for $10 \mathrm{~min}$. The protein concentration in the supernatant was measured according to the Bradford method. ${ }^{20}$ Before being used, the sample solution was diluted to concentrations of $0.04 \mathrm{mg} \mathrm{mL} \mathrm{m}^{-1}$. The fluorescence intensity of the samples was performed with an F-7000 fluorescence spectrophotometer (Hitachi Co., Tokyo, Japan) at room temperature. Intrinsic spectra were recorded between 300 and $500 \mathrm{~nm}$ with an excitation wavelength of $295 \mathrm{~nm}$ (slit $=2.5 \mathrm{~nm})$ at $10 \mathrm{~nm} \mathrm{~s}^{-1}$ of scanning speed.

\subsection{Surface hydrophobicity}

The surface hydrophobicity $\left(H_{0}\right)$ of each sample was measured following the method described by Kato and Nakai ${ }^{21}$ using 1anilino-8-naphthalene sulfonate (ANS). Protein solutions were prepared in phosphate buffer $(10 \mathrm{mM}, \mathrm{pH}$ 7.0) and stirred for $20 \mathrm{~min}$, then centrifuged at $5000 \mathrm{rpm}$ for $10 \mathrm{~min}$. The protein concentration in the supernatant was measured according to the Bradford method..$^{20}$ Before being used, the sample solution was diluted to concentrations of $0.2 \mathrm{mg} \mathrm{mL}^{-1}$ to $0.8 \mathrm{mg} \mathrm{mL}^{-1}$. Then, $1 \mathrm{~mL}$ sample solution was mixed with $12.5 \mu \mathrm{L}$ ANS $(8 \mathrm{mM}$ in $10 \mathrm{mM}$ phosphate buffer, $\mathrm{pH}$ 7.0). The fluorescence intensity was measured at wavelengths of $365 \mathrm{~nm}$ (excitation) and $484 \mathrm{~nm}$ (emission) using an F-7000 fluorescence spectrophotometer (Hitachi Co., Tokyo, Japan). The surface hydrophobicity index was defined as the initial slope of the plot of fluorescence intensity as a function of protein concentration.

\subsection{Sulfhydryl and disulfide bond content}

The exposed sulfhydryl group $\left(\mathrm{SH}_{\mathrm{E}}\right)$, total sulfhydryl group $\left(\mathrm{SH}_{\mathrm{T}}\right)$, and disulfide bond (S-S) content of the protein samples were determined using Ellman assays. For $\mathrm{SH}_{\mathrm{E}}$ content determination, $1.5 \mathrm{mg} \mathrm{mL}^{-1}$ protein samples were prepared with Tris-Gly buffer $\left(0.1 \mathrm{~mol} \mathrm{~L}^{-1}, \mathrm{pH}\right.$ 8.0). Then, $50 \mu \mathrm{L}$ Ellman' $\mathrm{s}$ reagent (DTNB in Tris-Gly buffer, $4 \mathrm{mg} \mathrm{mL}^{-1}$ ) was added to $1 \mathrm{~mL}$ protein solution. After binding for $5 \mathrm{~min}$ at room temperature, the mixture was centrifuged at $10000 \times g$ for $15 \mathrm{~min}$. Absorbance of the supernatant at was then measured $412 \mathrm{~nm}$. 


\subsection{X-ray photoelectron spectroscopy (XPS) measurements}

X-ray photoelectron spectroscopy measurements were carried out with AXIS Supra by Kratos Analytical Inc. using monochromatized $\mathrm{Al} \mathrm{K} \alpha$ radiation $(h \nu=1486.6 \mathrm{eV}, 225 \mathrm{~W})$ as X-ray source with a base pressure of $10^{-9}$ Torr. Survey scan spectra were acquired using a pass energy of $160 \mathrm{eV}$ and a $1 \mathrm{eV}$ step size. Narrow region scans were acquired using a pass energy of $40 \mathrm{eV}$ and a $0.1 \mathrm{eV}$ step size. The hybrid lens mode was used in both cases. The analyzed area of all XPS spectra was $300 \times 700 \mu \mathrm{m}^{2}$. A charge neutralizer was used throughout as the samples were mounted such that they were electrically isolated from the sample bar. All spectrums were calibrated by C $1 \mathrm{~s}(284.8 \mathrm{eV})$.

\subsection{Emulsifying properties}

Emulsifying capacity (EC) and emulsifying stability (ES) were determined using the turbidimetric method. ${ }^{22}$ A 1\% RDP solution was prepared in phosphate buffer $(10 \mathrm{mM}, \mathrm{pH} 7.0)$. Then, $15 \mathrm{~mL}$ sample solution was mixed with $5 \mathrm{~mL}$ of peanut oil and homogenized at $15000 \mathrm{rpm}$ for $1 \mathrm{~min}$ at room temperature with a homogenizer (T18BS25, IKA, Germany). A $50 \mu \mathrm{L}$ aliquot of the emulsion sample was taken from the bottom of the test tube at 0 and $20 \mathrm{~min}$ and immediately dispersed into $5 \mathrm{~mL}$ of $0.1 \%$ SDS solution. The absorbance of the emulsion was measured at $500 \mathrm{~nm}$ with a spectrophotometer (UV-1800, Shimadzu, Japan). The EC was defined as the absorbance that was measured immediately after emulsion formation $\left(A_{0}\right)$. The ES was determined as follows:

$$
\operatorname{ES}(\%)=\left(A_{0}-A_{10}\right) / A_{0} \times 100
$$

where $A_{10}$ is the absorbance measured at $10 \mathrm{~min}$.

\subsection{Foaming properties}

Foaming capacity (FC) and foaming stability (FS) were determined following the method described by Liu et al. ${ }^{23}$ with slight modifications. A volume of $50 \mathrm{~mL}$ of $0.5 \%$ sample solution was added into a $250 \mathrm{~mL}$ cylinder and homogenized (T18BS25, IKA, Germany) at a speed of $15000 \mathrm{rpm}$ for $1 \mathrm{~min}$ at room temperature. The foam volumes were measured immediately $\left(V_{0}\right)$ and after standing for $60 \mathrm{~min}\left(V_{60}\right)$. FC was expressed as $V_{0}$. The ES was determined as follows:

$$
\mathrm{FS}(\%)=V_{60} / V_{0} \times 100
$$

\subsection{Water absorption capacity (WAC) and oil absorption capacity (OAC)}

The sample $(0.1 \mathrm{~g})$ was suspended in $1 \mathrm{~mL}$ of distilled water or peanut oil, vortexed intermittently and centrifuged at $1500 \mathrm{~g}$ for $15 \mathrm{~min}$. Then, the aqueous supernatant or clear oil obtained after centrifuging was decanted. WAC and OAC were calculated as gram of water or oil absorbed per gram of sample, respectively.

\subsection{Statistical analysis}

IMB SPSS statistics 2.0 software was used to analyze the data. The differences between the mean values of the samples were determined using the least significant difference (LSD) test at a significance level of 0.05 .

\section{Results and discussion}

\subsection{Effect of EBI pretreatment on the microcosmic surface structure of RPs}

Fig. 1 shows the scanning electron microscope microphotographs of rice protein irradiated at different doses. As shown in Fig. 1A, nonirradiated RPs appeared to have globular aggregate structures, which were tight and rough. Moreover, the overall structures were intact. When RPs were subjected to a $5 \mathrm{kGy}$ irradiation dose (Fig. 1B), tight aggregation was broken down and the proportion of small sized granules was increased; however, the surface structure remained compact compared with nonirradiated RPs. As shown in Fig. 1C, the structural integrity of RPs irradiated at $10 \mathrm{kGy}$ decreased and fragments and cracks emerged compared with the nonirradiated RPs and the RPs irradiated at $5 \mathrm{kGy}$. As the irradiation dose continues to rise, the surface structure became loose and a large number of smaller fragments are observed (Fig. 1D and E). This type of breakage could be ascribed to the disintegration of rice protein caused by the highly energetic electron beams. The results revealed that the microcosmic surface structures of the RPs were obviously destroyed by the irradiation and that the degree of damage was enhanced by increasing the intensity of the treatment dose. Similar results were previously reported by Zhao et al. They observed that puncture pores appeared on the surface structure of the protein and the number of small fragments increased as the irradiation dose increased. Deformation of the protein has also been reported by Malik et al. in that gamma irradiation induced cracks on the surface of sunflower protein isolates. However, Wang et al. found that there were no obvious differences between the control and irradiated samples in terms of the microstructures of the proteins, indicating there was minimal degradation or aggregation of protein molecules in their solid form. Currently, two types of radiation damage to proteins have been observed: fragmentation and aggregation. As shown in Fig. 1, a broken protein surface and stratified structure do exist. Thus, this indicates that fragmentation resulting from irradiation damage occurred on the RPs surface, increased the proportion of small sized granules and enlarged the specific surface area, which may further influence the proteins' performance.

\subsection{Effect of EBI pretreatment on the conformation of RPs}

3.2.1 UV visible spectra analysis. The effects of EBI treatment with different irradiation doses on the UV visible spectra of RPs are shown in Fig. 2A. The characteristic absorption, which has an absorbance maximum of approximately $278 \mathrm{~nm}$, was mainly ascribed to the presence of tyrosine, tryptophan and phenylalanine. $^{24}$ The absorbance intensities of the RPs were strengthened after electron beam treatment. At the same time, 

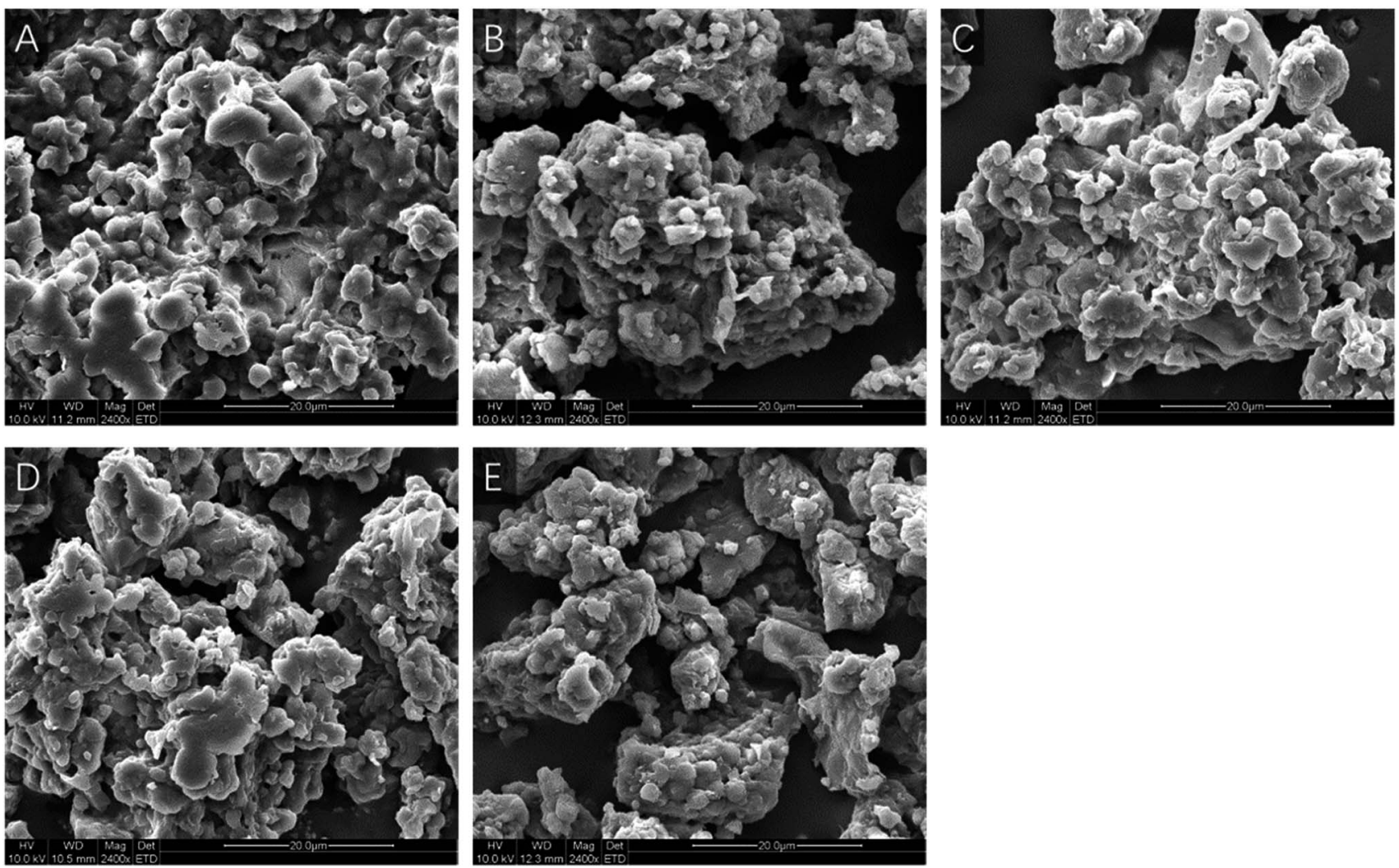

Fig. 1 The scanning electron microscope microphotographs of rice protein irradiated by different doses. Figure numbered (A, B, C, D and E) were the microphotographs of RP irradiated by 0, 5, 10, 20 and 30 kGy at 2400x magnification, respectively.

the absorption intensity increased significantly in response to increases in the irradiation dose. The reasons for this might be EBI-induced unfolding of protein molecules and subsequent exposure of the buried hydrophobic groups. Moreover, changes in the secondary structure may also contribute to the enhancement of the absorption intensity. Similar findings were reported by Lee et al. when using gamma irradiation to pretreat myoglobin. ${ }^{25}$

3.2.2 Fourier transform infrared spectroscopy (FTIR) analysis. A FTIR experiment was conducted to further study the effects of EBI on conformational changes in RPs. On the FTIR spectrum, the stronger the light absorption intensity of a compound at a certain wavenumber, the lower the transmittance of this wavenumber, and an inverted peak will be displayed on the infrared spectrum. The FTIR spectra of the RPs are illustrated in Fig. 2B. It was observed that all of the samples had the same FTIR absorption pattern, revealing that no major chemical functional group transformation occurred due to electron beam irradiation. ${ }^{26}$ The spectra did not change; however, a reduction in the transmittance value of the samples was observed with increases in irradiation dose, which indicated that an increase of EBI treatment dose could increase the absorption strength of RPs. The adsorption intensities in the bands at $3600-3300 \mathrm{~cm}^{-1}$, which are related to the $\mathrm{O}-\mathrm{H}$ and $\mathrm{N}-\mathrm{H}$ stretching vibrations, ${ }^{27}$ were enhanced by EBI treatment. The results demonstrated that EBI treatment can enhance hydrogen bonds within and between protein molecules.
Additionally, the amide bands' intensities increased between 5 kGy and 10 kGy much more significantly than between 0 and 5; 10 and 20;20 and 30. This may be because the energy produced by the electron beam affected the chemical bonds of the proteins to different degrees. The energy generated by low EBI irradiation does $(5 \mathrm{kGy})$ was too small to induce obvious vibration change of the chemical bonds in protein. When the irradiation does increase to $10 \mathrm{kGy}$, the energy generated by EBI irradiation had a significant influence on protein structure and resulted in dramatical changes on the intensity of chemical bond vibration. However, when the radiation dose continued to increase, the energy produced by the electron beam was larger, but the effect on the structure of the protein tended to be saturated, therefore, the increase in the vibration strength of the chemical bond decreased. The results showed that although EBI treatment had an effect on the structure of protein, its effect tended to decrease with the increase of irradiation dose. An FTIR spectrum of $1480-1200 \mathrm{~cm}^{-1}$ was the fingerprint region of the protein. The untreated group and the EBI-treated groups showed similar fingerprints (Fig. 2C), indicating that there were no significant differences in the compositions of these samples.

Fig. 2D shows the amide II band (1560-1500 $\left.\mathrm{cm}^{-1}\right)$ of rice protein irradiated by $0,5,10,20$ and $30 \mathrm{kGy}$. The amide II infrared absorption peak intensity can reflect the conformational changes of the tertiary structure of a protein. Tang et al. observed that the amide II peak intensity of soybean protein isolate increased in response to high pressure treatment, and 

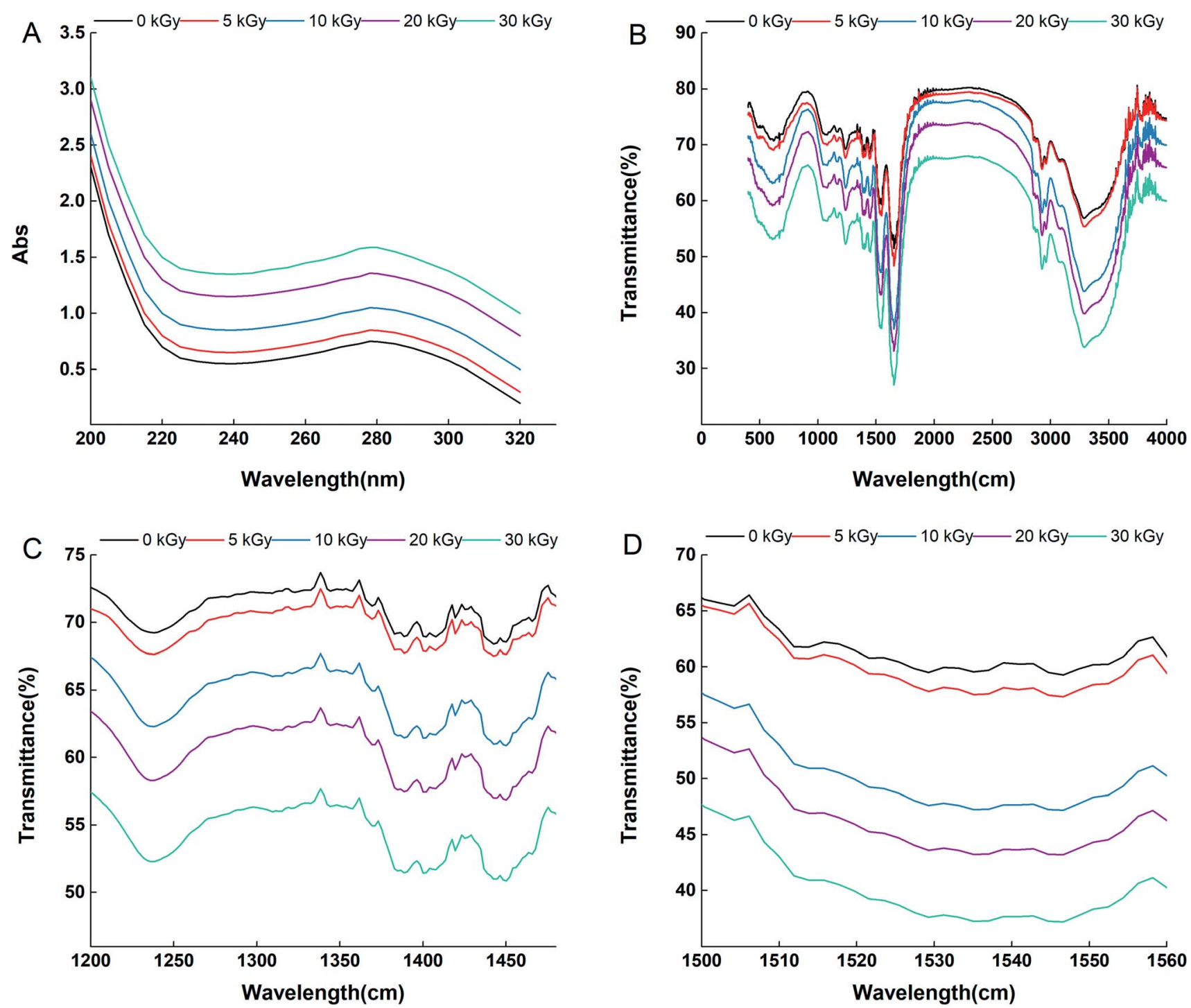

Fig. 2 The UV spectra (A), FTIR spectra (B), fingerprint bands $\left(1480-1200 \mathrm{~cm}^{-1}\right.$ ) and (C) amide II region (1560-1500 cm $\left.{ }^{-1}\right)(D)$ of rice protein irradiated by $0,5,10,20$ and 30 kGy.

the phenomenon was attributed to the unfolding of the protein tertiary structure. ${ }^{28}$ In this study, the peak intensity in the amide II region of the irradiated samples increased significantly with the increase in irradiation dose, indicating that the expansion degree of the RPs tertiary structure increased with the increase in the EBI treatment dose. This result is consistent with that determined by the UV visible spectra. However, the wavenumbers of most peaks in the amide II area were almost unaffected by EBI treatment, which indicates that the maintenance of the tertiary structure of RPs is mainly related to hydrophobic interactions and has nothing to do with hydrogen bonds within molecules.

The amide I band (1700-1600 $\mathrm{cm}^{-1}$ ) mainly comprises the $\mathrm{C}=\mathrm{O}$ stretching vibration of the polypeptide chain; therefore, it can be used to discern $\alpha$-helices, $\beta$-sheets, $\beta$-turns, and random coils through proper fitting to this area. ${ }^{29}$ In this study, FTIR analysis of the amide I band demonstrated that the secondary structural components changed considerably after EBI treatment (Table 1). Moreover, the changes were proportional to the irradiation dose. Compared to the nonirradiated group, EBI resulted in a maximum reduction of $\alpha$-helices by $64.09 \%$ and an increase in $\beta$-sheets, $\beta$-turns and random coils by $16.44 \%$, $8.03 \%$ and $28.07 \%$, respectively. These results are consistent with those of Malik et al., who reported that gamma irradiation resulted in a decrease in $\alpha$-helix structure and an increase in $\beta$ sheet, $\beta$-turn and random coil content compared to nonirradiated sun flower protein isolates. ${ }^{30}$ The $\alpha$-helix structure is susceptible to conformational changes, and a reduction in its content might be related to partial unfolding of the protein, which results in exposure of buried groups. ${ }^{31,32}$ An increase in $\beta$ sheets and random coils may lead to loosening of the protein molecule while an increase in $\beta$-turns may promote protein aggregation. ${ }^{33}$ Based on these findings, we suggest that EBI 
Table 1 Estimation of secondary structure content of rice protein irradiated by electron beam

\begin{tabular}{|c|c|c|c|c|c|}
\hline & \multicolumn{5}{|c|}{ Irradiation does } \\
\hline & 0 kGy & 5 kGy & 10 kGy & $20 \mathrm{kGy}$ & 30 kGy \\
\hline$\beta$-Sheet & $31.03 \pm 0.20$ & $32.07 \pm 0.19$ & $32.89 \pm 0.19$ & $35.61 \pm 0.12$ & $36.13 \pm 0.23$ \\
\hline$\beta$-Turn & $29.90 \pm 0.34$ & $30.30 \pm 0.47$ & $31.80 \pm 0.40$ & $31.90 \pm 0.36$ & $32.30 \pm 0.21$ \\
\hline Random roils & $19.01 \pm 0.15$ & $19.30 \pm 0.27$ & $20.01 \pm 0.23$ & $23.40 \pm 0.18$ & $24.46 \pm 0.33$ \\
\hline
\end{tabular}

changed the conformation of the proteins and caused unfolding of the RPs.

3.2.3 Intrinsic fluorescence analysis. The tryptophan fluorescence spectrum mainly reflects the changes in the polarity of the tryptophan microenvironment and can be used to sensitively detect changes in protein conformation at the level of the tertiary structure. The increase in the protein maximum absorption wavelength of the fluorescence mission peak $\left(\lambda_{\max }\right)$ is redshifted. In general, the redshift of $\lambda_{\max }$ indicates that the fluorescent emission group is exposed to the solvent and the protein molecules thus unfold. The magnitude of the redshift represents the degree to which the protein conformation changes. In this study, the intrinsic fluorescence spectra (IFS) of proteins irradiated by an electron beam were measured and the results are shown in Fig. 3. The fluorescence peak of native rice protein appeared at $335 \mathrm{~nm}$, which is the typical tryptophan fluorescence spectrum, indicating that tryptophan residues are located in the hydrophobic region of the rice protein, such as the interior of the protein molecules. In EBI treatment (Fig. 3B), gradual increases in emission intensity and redshifts (from 335 to $347 \mathrm{~nm}$ ) of the maximum with an increase in irradiation doses were observed. Generally, tryptophan is partially buried in a folded protein structure and dominates the fluorescence spectrum when excited at $295 \mathrm{~nm} \cdot{ }^{34}$ From the redshifts of intrinsic fluorescence spectroscopy induced by EBI as shown in Fig. 3B, it could be deduced that EBI treatment could disrupt the stable protein molecules, induce the unfolding of native proteins and lead to tryptophan residues being exposed to the polar solvent. ${ }^{35}$ Conversely, the increased fluorescence intensity (Fig. 3B) also reflected that tryptophan residues are more exposed after EBI treatment. It is known that the energy transfer from tyrosine to tryptophan (which depends on the distance between the two residues) and fluorescence quenching of the adjacent groups affects the fluorescence intensity of tryptophan at $295 \mathrm{~nm}$. Therefore, a potential reason for the enhancement of tryptophan fluorescence intensity might be the conformational changes caused by EBI, which moves the tryptophan residues closer to the tyrosine residues or further away from the fluorescence quenching groups.

3.2.4 Surface hydrophobicity. Hydrophobic interactions are the dominant force maintaining the tertiary structure of proteins. They play an important role in the stability of the protein structure and its functional properties. ${ }^{36}$ In general, the surface hydrophobicities $\left(H_{0}\right)$ of proteins can be used to evaluate changes in protein structure. Table 2 shows the $H_{0}$ values of rice protein irradiated at various dose levels. Treatment of proteins with EBI increased the $H_{0}$ values of all irradiated proteins when compared to unmodified protein, indicating that EBI could significantly disrupt the stable conformation of the protein. Moreover, the degree of damage was associated with the dose and the value of $H_{0}$ was increased with the increase in dose. Hydrophobic amino acid residues are known to be located
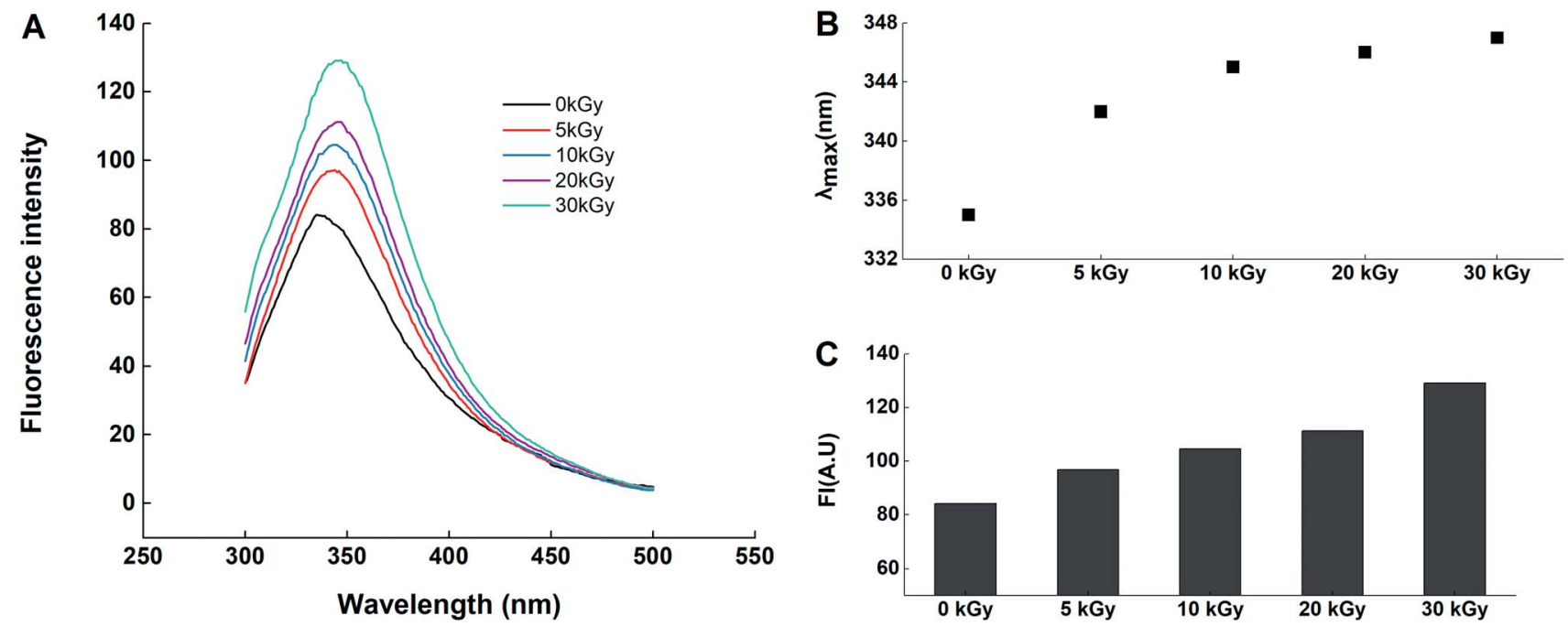

Fig. 3 The intrinsic fluorescence spectroscopy (A) and maximum absorption wavelength (B) and maximum fluorescence intensity (C) of rice protein irradiated by $0,5,10,20$ and 30 kGy. 
Table 2 The sulfhydryl groups contents of rice protein irradiated by electron beam

\begin{tabular}{lrrll}
\hline & \multicolumn{4}{l}{$\mathrm{SH}$ and S-S contents $\left(\mu \mathrm{mol} \mathrm{g}^{-1}\right.$ protein $)$} \\
\cline { 2 - 5 } Treatment & \multicolumn{1}{c}{$H_{0}$} & \multicolumn{1}{l}{$\mathrm{SH}_{\mathrm{E}}$} & \multicolumn{1}{l}{$\mathrm{SH}_{\mathrm{T}}$} & \multicolumn{1}{l}{$\mathrm{S}-\mathrm{S}$} \\
\hline $0 \mathrm{kGy}$ & $97.33 \pm 1.15$ & $7.63 \pm 0.13$ & $37.98 \pm 0.41$ & $41.75 \pm 0.36$ \\
$5 \mathrm{kGy}$ & $112.27 \pm 2.23$ & $8.09 \pm 0.19$ & $32.88 \pm 0.62$ & $44.11 \pm 0.62$ \\
$10 \mathrm{kGy}$ & $117.67 \pm 3.15$ & $8.87 \pm 0.12$ & $28.12 \pm 0.54$ & $52.73 \pm 0.52$ \\
$20 \mathrm{kGy}$ & $178.00 \pm 2.62$ & $10.25 \pm 0.24$ & $25.16 \pm 0.23$ & $55.96 \pm 0.24$ \\
$30 \mathrm{kGy}$ & $189.01 \pm 2.00$ & $11.36 \pm 0.15$ & $23.77 \pm 0.47$ & $58.44 \pm 0.71$
\end{tabular}

in the interiors of protein molecules. This feature is lost when protein molecules are subjected to external forces, such as heating. ${ }^{37}$ The increased $H_{0}$ values demonstrate that electron beam irradiation can induce protein degeneration. When proteins undergo degeneration, their tight structure unfolds, exposing the hydrophobic groups and increasing the relative number of hydrophobic residues on the protein surface, thus promoting the availability of hydrophobic zones that may be accessible to an ANS fluorescence probe. These results are in agreement with those of Wang et al., who found that the surface hydrophobicity of pea protein hydrolysates is enhanced by EBI. ${ }^{2}$

3.2.5 Sulfhydryl and disulfide bond contents. The sulfhydryl and disulfide bonds of proteins are highly active and can be converted into one another through the $-\mathrm{SH} / \mathrm{S}-\mathrm{S}$ exchange reaction, which plays an important role in the functional properties of proteins. ${ }^{38}$ Many physical and chemical treatments, such as ultrasound and heating, ${ }^{39,40}$ cause changes in sulfhydryl and disulfide bonds, leading to protein denaturation. Therefore, the changes in protein structure can be evaluated by determining the content of the sulfhydryl groups. As listed in Table 2, the $\mathrm{SH}_{\mathrm{E}}$ contents of the samples pretreated by EBI were markedly higher than that of the control. At the same time, it was observed there was a dose-dependent change in the $\mathrm{SH}_{\mathrm{E}}$ content, with maximum levels occurring at $30 \mathrm{kGy}$ (increased by $48.49 \%$ vs. the control group). The results showed that the $-\mathrm{SH}$ groups inside molecules were exposed to the surface because of the unfolding of protein molecules, which is consistent with the results of the surface hydrophobicity study (Fig. 3). It was also found that EBI pretreatment of rice proteins resulted in a reduction in $\mathrm{SH}_{\mathrm{T}}$ and an increase in $\mathrm{S}-\mathrm{S}$, which can be ascribed to the $-\mathrm{SH} / \mathrm{S}-\mathrm{S}$ exchange reaction during protein unfolding. When proteins undergo denaturation induced by EBI, the ordered structures of the proteins are destroyed, exposing the reactive $\mathrm{SH}$ groups, which are prone to oxidation into disulfide bonds. Moreover, the effect of $\mathrm{EBI}$ on $\mathrm{SH}_{\mathrm{T}}$ and $\mathrm{S}-\mathrm{S}$ content was enhanced as the irradiation dose increased. These findings are consistent with those of previous research that has shown that the $-\mathrm{SH}$ content in myofibrillar proteins from Tegillarca granosa meat decreased as the electron beam dose increased. ${ }^{41}$

On the other hand, X-ray photoelectron spectroscopy (XPS) analysis was conducted to further confirm the surface chemical environment changes of the EBI treated rice protein. ${ }^{42-44}$ Fig. 4 shows the $S 2 p_{3 / 2}$ XPS spectra of rice protein irradiated by $0 \mathrm{kGy}$

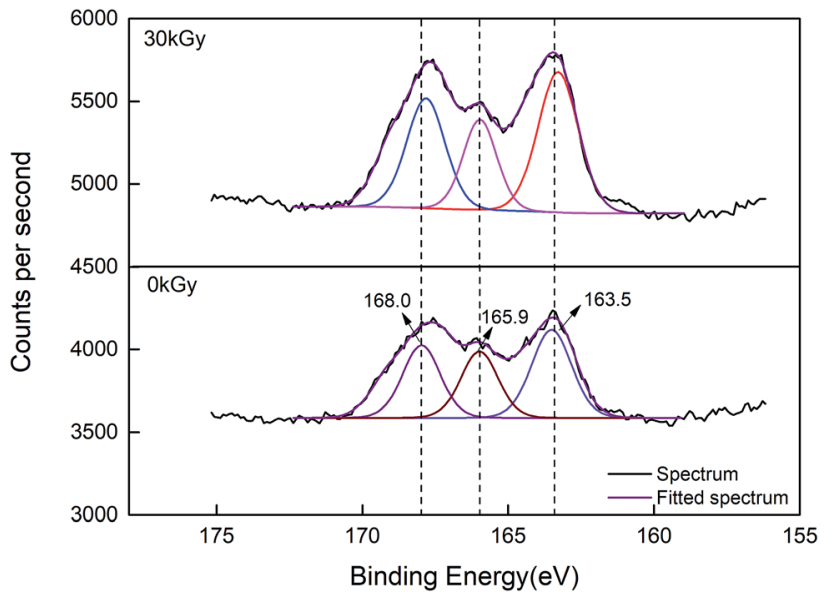

Fig. 4 The $S 2 p_{3 / 2}$ XPS spectra of rice protein irradiated by 0 kGy and 30 kGy

and $30 \mathrm{kGy}$. The $\mathrm{S} 2 \mathrm{p}_{3 / 2}$ peaks located at 163.5 and $168.0 \mathrm{eV}$ suggested the present of $-\mathrm{SH}$ and $\mathrm{S}-\mathrm{S} .{ }^{45}$ Compared with the untreated rice protein, the $\mathrm{S} 2 \mathrm{p}_{3 / 2}$ peaks for the EBI treated rice protein ( $30 \mathrm{kGy}$ ) are located at $163.3 \mathrm{eV}$ and $167.9 \mathrm{eV}$, being shifted slightly by about $0.1-0.2 \mathrm{eV}$ toward lower binding energies owing to the $-\mathrm{SH} / \mathrm{S}-\mathrm{S}$ exchange reaction.

The results of the sulfhydryl group analysis and XPS analysis combined with those of the UV visible spectra, FTIR analysis, surface hydrophobicity and internal fluorescence determination indicated that electron beam irradiation will lead to protein denaturation and open the compact structure. As a consequence, the protein structure becomes more flexible, and many groups buried inside the molecules are exposed. These changes in protein structure may affect the functional properties and biological activities of the proteins.

\subsection{Effect of EBI pretreatment on the functional properties of RPs}

3.3.1 Emulsifying properties. The emulsifying abilities (EAs) and emulsion stabilities (ESs) of rice proteins prepared with electron beams are shown in Fig. 5A and B. The two parameters are generally used to investigate the emulsifying properties of proteins in food emulsion systems. As seen, the EAs of the irradiated samples were 0.48-0.72 (much higher than the nonirradiated group), which rapidly increased with an increase in irradiation dose. This result is in agreement with previous studies using pea protein and wheat protein, ${ }^{2,18}$ indicating that EBI may serve as an effective method to promote the emulsion capacity of rice protein. There are many factors that affect protein emulsification properties, and $H_{0}$ is one of the most important factors that determines the emulsifying capacity. ${ }^{46}$ The exposed hydrophobic groups promote adsorption and diffusion between protein and oil, enhancing the emulsifying capacity of the protein. According to Venkatesh et al. ${ }^{47}$ when proteins undergo denaturation, their conformational structures unfold and more hydrophobic groups are exposed on the protein surface, thereby facilitating the 

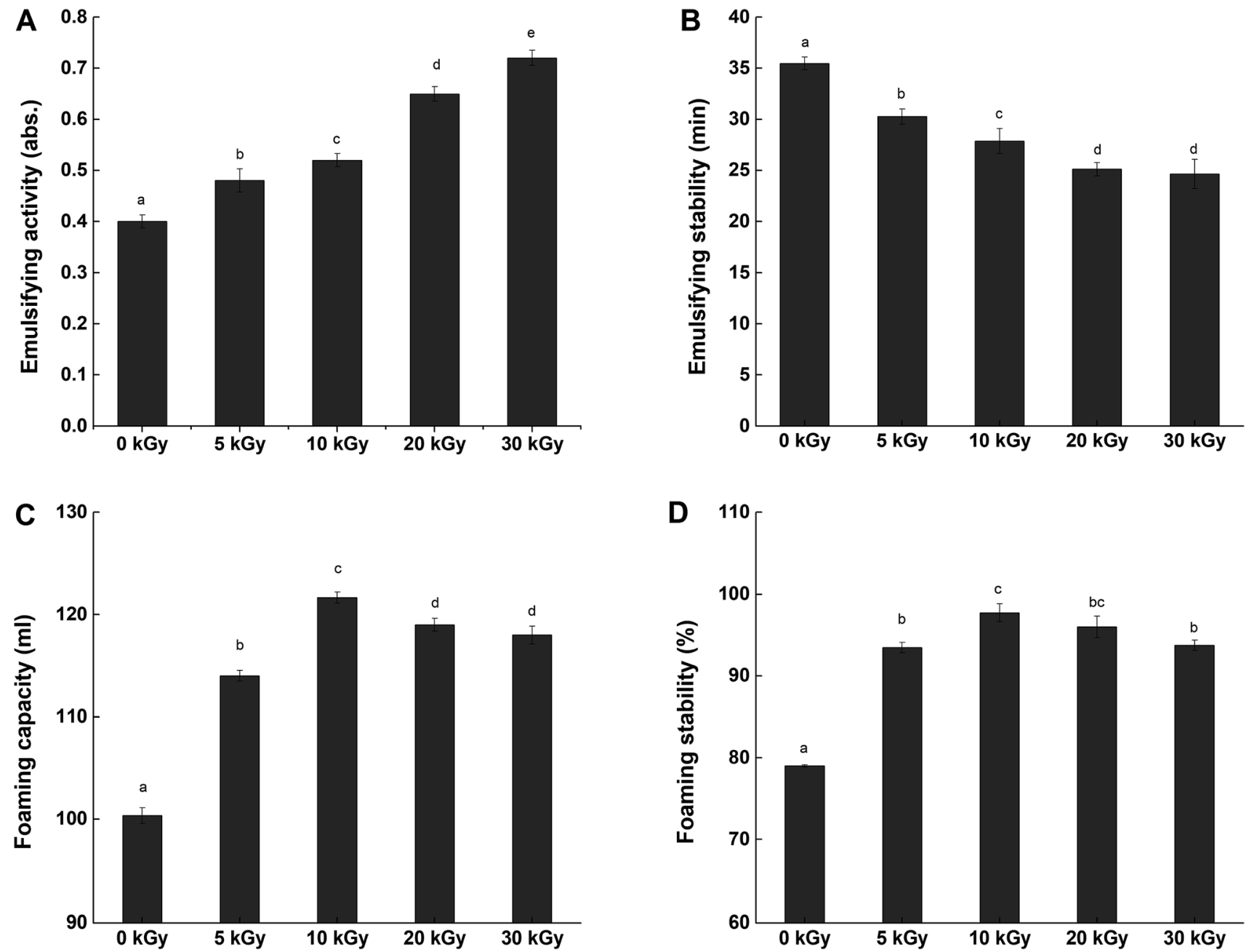

Fig. 5 Emulsifying activity (A), emulsifying stability (B), foaming capacity (C) and foaming stability (D) of rice protein irradiated by $0,5,10,20$ and $30 \mathrm{kGy}$. The values reported represent the mean \pm SD $(n=3)$.

interaction between proteins and oils. This leads to similar trends in emulsifying properties as that of $H_{0}$, as verified by the results of this study.

In contrast, all of the samples irradiated by electron beams presented with lower ESs than the control (0 kGy). Meanwhile, the loss of stability became poorer as the irradiation dose increased. This result indicates that the emulsions formed by the irradiated proteins were vulnerable to environmental conditions. The decrease of emulsion stability is possibly due to the higher surface hydrophobicity, which would be expected to result in the flocculation of oil droplets. ${ }^{48}$

3.3.2 Foaming properties. Generally, foams are a type of colloid system of tiny bubbles dispersed in a continuous phase of water. The foaming stability of a protein represents the reduction rate in the surface tension of the air/water interface. ${ }^{\mathbf{4 9}}$ The foam capacities (FC) and stabilities (FS) of RPs modified by EBI are given in Fig. 5C and D. It is obvious that rice protein samples that were irradiated under various doses showed better FC and FS than samples without irradiation $(P<0.05)$. However, the foaming properties of the RPs were not dose-dependent. The FCs of RPs initially increased as the irradiation dose increased but then slightly decreased as the dose continued to increase. The maximum value of FC appears at $10 \mathrm{kGy}$, an increase of $18.00 \%$ compared with the control. A similar trend was observed for foam capacity, where the highest FS was found at $10 \mathrm{kGy}$, which is an increase of $15.20 \%$. Generally, FC depends on the diffusion rate and the denaturation rate of proteins at the interface, while the stability of the foam is closely related to the strength of the membrane formed by the proteins and the permeability of the bubbles. At the same time, these factors are connected to the flexibility, conformation and surface hydrophobicity of a protein molecule. ${ }^{50}$ According to Tang et al., flexible protein molecules with few secondary and tertiary structures are needed to form cohesive layers around gas/air droplets. ${ }^{51}$ Ma et al. reported that conformational changes of proteins that which increased surface hydrophobicity improved the foaming ability of egg whites. Based on these findings, it could be assumed that EBI induced protein scission and conformational changes, which are indicated by the previous results obtained from the structure analysis mentioned above and would have given rise to an improvement in foaming properties. Moreover, the irradiated rice protein had 
more flexible randomly coiled structures (Table 1), which induced the protein to undergo rapid conformational changes at the air-water interface with reduced surface tension, which enhanced their foaming properties. ${ }^{52}$ However, as the irradiation dose increased ( $>10 \mathrm{kGy}$ ), there were increasing numbers of protein molecules with low molecular weights, which led to their inability to form a stable adhesive layer around the foam, thus reducing the quality of the bubbles. Several studies have reported that the foaming properties of samples are increased by irradiation. Wang et al. (2017) reported that the foaming ability of pea protein hydrolysates was improved after 10 kGy irradiation. The increased foaming properties may be attributed to irradiation-induced breakdown of proteins that increase the surface hydrophobicity and lower the molecular weight. ${ }^{2}$ They also reported improved functional properties in defatted wheat germ proteins irradiated at $30 \mathrm{kGy}$ or above because irradiation caused the loss of ordered secondary structures and the formation of more flexible structures, enhancing some functional properties. ${ }^{18}$ In addition, Clark et al. demonstrated that irradiation causes changes in the secondary structures of proteins and enhances some functional properties in spraydried egg white. ${ }^{53}$ These findings, in combination with the data from the present study, suggest that EBI can significantly influence the foaming ability of food samples and may be an effective method for producing products with high foaming properties.

3.3.3 Water and oil adsorption capacity. Water absorption capacity (WAC) provides insights into the ability of a product to associate with water under a limited water condition. ${ }^{54}$ It helps to retain freshness and mouth feel..$^{55}$ As reported in Fig. 6, all irradiated samples exhibited better water adsorption capacities than the control ( $0 \mathrm{kGy}$ ) after exposure to the electron beam for the same amount of time. The largest increase in WAC occurred at $30 \mathrm{kGy}$, which was an increase of $62.25 \%$ compared to the control group. These phenomena showed that irradiation had an apparent effect on the WACs of RPs. This may be due to the denaturation effects of irradiation on proteins. By contacting the exposed product, electron beams induced protein unfolding and ensured the exposure of hydrophobic groups. Consequently, the number of polar amino groups for water binding increased, ${ }^{56}$ resulting in the enhancement of WAC.

Oil absorption capacity (OAC) also plays an important role in enhancing mouth feel and maintaining flavor. ${ }^{57}$ The OACs of native and irradiated proteins are presented in Fig. 6 . The OAC values of irradiated RPs presented marked increases when compared with the unmodified sample. As the irradiation dose increased, the OAC values increased up to a maximum value $\left(2.81 \pm 0.07 \mathrm{~g} \mathrm{~g}^{-1}\right)$ at $30 \mathrm{kGy}$, which was an increase of $81.25 \%$. There are many factors that can affect the OAC, such as surface hydrophobicity, physical entrapment of oil and macromolecule size. ${ }^{58}$ The increase in the OAC can be attributed to the partial unfolding of proteins in response to irradiation, causing more nonpolar protein residues inside the molecules to be exposed, which enhanced the interactions between the protein and the oil.
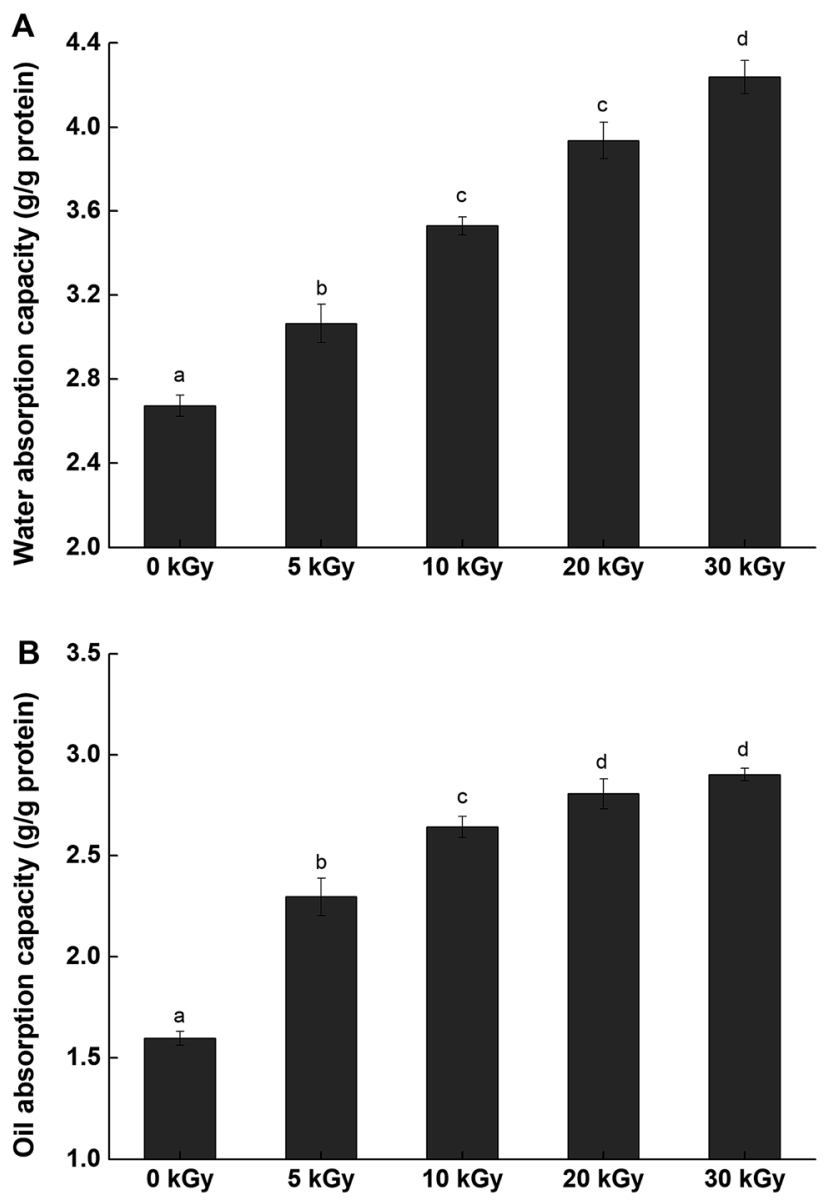

Fig. 6 Water adsorption capacity (A) and oil adsorption capacity (B) of rice protein irradiated by $0,5,10,20$ and $30 \mathrm{kGy}$. The values reported represent the mean $\pm \mathrm{SD}(n=3)$.

\section{Conclusion}

Rice proteins showed considerable changes after electron beam irradiation in terms of structure. The microcosmic surface structure of the RPs was changed and fragmentation occurred on the RPs surface. The microenvironment of tryptophan became more exposed, as shown by the UV visible spectrum and the endogenous fluorescence spectrum. Redistribution of the secondary structure was observed with a decrease in $\alpha$-helices and concomitant increases in $\beta$-sheets, $\beta$-turns and random coils. The molecular mechanism of the responses of RPs pretreated by electron beams was also investigated, including the exposure of hydrophobic groups and the increase in $\mathrm{SH}_{\mathrm{E}}$ content. In terms of functional properties, the emulsifying ability, water adsorption capacity and oil adsorption capacity of the irradiated rice protein was improved dose-dependently, with a maximum occurring at $30 \mathrm{kGy}$. The foaming properties were also enhanced by electron beam irradiation; however, the effect was not dose-dependent. In contrast, all of the samples irradiated by electron beams presented lower emulsion stabilities than the control ( $0 \mathrm{kGy}$ ). Structural analysis demonstrated that EBI induces conformational changes and fragmentation of 
rice protein and enhances the release of many buried groups that are closely related to protein functions, thereby improving its functional properties. These results provide a theoretical basis for the application of EBI in improving protein properties in the future.

\section{Conflicts of interest}

There are no conflicts to declare.

\section{Acknowledgements}

Financial support for this research was provided by National Natural Science Foundation of China (No. 31471616), National Key R\&D Program of China (2017YFD0401200), National Top Youth Talent for Grain Industry of China (LQ2016301), Special Scientific Research Project in Grain Public Welfare Industry (201513004) and National First-class Discipline Program of Food Science and Technology (JUFSTR20180203).

\section{References}

1 F. F. Shih, Mol. Nutr. Food Res., 2003, 47, 420-424.

2 L. Wang, X. Zhang, F. Liu, Y. Ding, R. Wang, X. Luo, Y. Li and Z. Chen, Innovative Food Science \& Emerging Technologies, 2017 , p. 41.

3 M. Shibasaki, S. Suzuki, H. Nemoto and T. Kuroume, J. Allergy Clin. Immunol., 1979, 64, 259-265.

4 M. Wang, N. S. Hettiarachchy, M. Qi, W. Burks and T. Siebenmorgen, J. Agric. Food Chem., 1999, 47, 411.

5 W. W. Koo and J. B. Lasekan, Minerva Pediatr., 2007, 59, 3541.

6 A. Fiocchi, M. Travaini, E. D'Auria, G. Banderali, L. Bernardo and E. Riva, Clin. Exp. Allergy, 2003, 33, 1576-1580.

7 Y. J. Chen, Y. Y. Chen, C. T. Wu, C. C. Yu and H. F. Liao, J. Cereal Sci., 2010, 51, 189-197.

8 X. Zhang, L. Wang, R. Wang, X. Luo, Y. Li and Z. Chen, Food Funct., 2016, 7, 1429-1437.

9 R. L. Burris, C. H. Xie, P. Thampi, X. L. Wu, S. B. Melnyk and S. Nagarajan, Atherosclerosis, 2010, 212, 107-115.

10 J. Chen, S. Liu, R. Ye, G. Cai, B. Ji and Y. Wu, J. Funct. Foods, 2013, 5, 1684-1692.

11 I. Paraman, N. S. Hettiarachchy and C. Schaefer, Cereal Chem., 2008, 85, 76-81.

12 T. Wang, H. Zhang, L. Wang, R. Wang and Z. Chen, Food Chem., 2015, 178, 82-88.

13 X. H. Li, Y. L. Liu, C. P. Yi, Y. H. Cheng, S. M. Zhou and Y. F. Hua, J. Chin. Cereals Oils Assoc., 2010, 51, 7-12.

14 A. A. Sadeghi, G. Raisali and M. Moradi, Anim. Feed Sci. Technol., 2007, 134, 140-151.

15 C. Y. Ma, M. R. Sahasrabudhe, L. M. Poste, V. R. Harwalkar, J. R. Chambers and K. P. J. O'Hara, Can. Inst. Food Sci. Technol. J., 1990, 23, 226-232.

16 H. P. Song, B. Kim, J. H. Choe, S. Jung, K. S. Kim, D. H. Kim and C. Jo, Radiat. Phys. Chem., 2009, 78, 217-221.

17 P. Supriya, K. R. Sridhar, S. Nareshkumar and S. Ganesh, Food Bioprocess Technol., 2012, 5, 1049-1060.
18 L. Wang, Y. Ding, X. Zhang, Y. Li, R. Wang, X. Luo, Y. Li, J. Li and Z. Chen, J. Food Eng., 2017, 202, 9-17.

19 A. Akbarian, M. Khorvash, G. R. Ghorbani, E. Ghasemi, M. Dehghan-Banadaky, P. Shawrang and M. H. Ghaffari, Livest. Sci., 2014, 168, 45-52.

20 M. M. Bradford, Anal. Biochem., 1976, 72, 248-254.

21 A. Kato and S. Nakai, Biochim. Biophys. Acta, 1980, 624, 1320.

22 K. N. Pearce and J. E. Kinsella, J. Agric. Food Chem., 1978, 26, 716-723.

23 S. Liu, C. Elmer, N. H. Low and M. T. Nickerson, Food Res. Int., 2010, 43, 489-495.

24 M. H. Simonian, Curr. Protoc. Cell Biol., 2002, 15, A.3B.1A.3B.7.

25 L. Yongwoo and S. Kyung Bin, J. Biochem. Mol. Biol., 2002, 35, 590-594.

26 H. K. S. Mudasir Ahmad Malik and C. Singh Saini, Food Hydrocolloids, 2017, 72, 312-322.

27 A. J. Peacock and A. Calhoun, Polym. Sci., 2006, 87, 171-181.

28 C. H. Tang and C. Y. Ma, LWT-Food Sci. Technol., 2009, 42, 606-611.

29 L. Gang, L. Ji, S. Ke, W. Su, C. Jiwang, L. Ying and H. Qingrong, J. Agric. Food Chem., 2009, 57, 4552-4558.

30 M. A. Malik, H. K. Sharma and C. S. Saini, Food Hydrocolloids, 2017, 72, 312-322.

31 H. W. Yeom, Q. H. Zhang and C. P. Dunne, Food Chem., 1999, 67, 53-59.

32 K. M. Mingchun Lv, H. Zhang, D. Xu and W. Yang, Food Chem., 2018, 254, 64-69.

33 J. Jian, H. Ma, W. Kai, E. G. A. Yagoub, J. Owusu, W. Qu, R. He, C. Zhou and X. Ye, Ultrason. Sonochem., 2015, 24, 55-64.

34 M. Parisi, A. Mazzini, R. T. Sorbi, R. Ramoni, S. Grolli and R. Favilla, Biochim. Biophys. Acta, 2003, 1652, 115-125.

35 Z. Wei and R. Yang, Eur. Food Res. Technol., 2008, 228, 47-54. 36 Y. Sun, J. Chen, S. Zhang, H. Li, L. Jing, L. Lu, H. Uluko, Y. Su, W. Cui and W. Ge, J. Food Eng., 2014, 124, 11-18.

37 S. Tang, N. S. Hettiarachchy, R. Horax and S. Eswaranandam, J. Food Sci., 2010, 68, 152-157.

38 W. Tao, F. Liu, W. Ren, W. Li, Z. Hao and Z. Chen, Food Funct., 2015, 6, 423-430.

39 A. C. Alting, M. Weijers, E. H. de Hoog, V. D. P. Am, M. A. Cohen Stuart, R. J. Hamer, C. G. de Kruif and R. W. Visschers, J. Agric. Food Chem., 2004, 52, 623-631.

40 J. Z. Chaoting Wen, J. Zhou, Y. Duan, H. Zhang and H. Ma, Ultrason. Sonochem., 2018, 49, 294-302.

41 K. M. Mingchun Lv, H. Zhang, D. Xu and W. Yang, Food Chem., 2018, 254, 64-69.

42 Y. Zhang and S. J. Park, J. Catal., 2018, 361, 238-247.

43 Y. Zhang and S. J. Park, J. Catal., 2017, 355, 1-10.

44 Y. Zhang and S. J. Park, Carbon, 2017, 122, 287-297.

45 P. S. Jin and Y. Zhang, J. Mater. Chem. A, 2018, 6, 2030420312.

46 E. Li Chan, S. Nakai and D. F. Wood, J. Food Sci., 2010, 49, 345-350.

47 A. Venktesh and V. Prakash, J. Agric. Food Chem., 1993, 41, 99-108. 
48 R. S. H. Lam and M. T. Nickerson, LWT-Food Sci. Technol., 2015, 60, 427-434.

49 P. J. Halling, Crit. Rev. Food Sci. Nutr., 1981, 15, 155-203.

50 B. Miroljub, C. Slavica, P. Mirjana, S. Sla Ana, P. E. Milica, M. E. Ognjen and R. Nikola, Int. J. Mol. Sci., 2011, 12, 8372-8387.

51 S. Tang, N. S. Hettiarachchy, R. Horax and S. Eswaranandam, J. Food Sci., 2003, 68, 152-157.

52 T. Wang, H. Zhang, L. Wang, R. Wang and Z. Chen, Food Chem., 2015, 178, 82-88.
53 D. C. Clark, I. F. Kiss, P. J. Wilde and D. R. Wilson, Food Hydrocolloids, 1992, 5, 541-548.

54 U. Singh, J. Food Sci. Technol., 2001, 38, 191-199.

55 G. K. Chandi and D. S. Sogi, J. Food Eng., 2007, 79, 592-597.

56 J. F. Zayas, Functionality of Proteins in Food, Springer, Berlin, Heidelberg, 1997.

57 J. E. Kinsella and N. Melachouris, Crit. Rev. Food Sci. Nutr., 1976, 7, 219-280.

58 W. Prinyawiwatkul, K. H. McWatters, L. R. Beuchat and R. D. Phillips, J. Agric. Food Chem., 1997, 45, 1891-1899. 